\title{
Viabilidade agroeconômica da consorciação do taro com feijão-vagem indeterminado em razão da época de plantio ${ }^{1}$
}

\author{
Janiele Cássia Barbosa Vieira², Mário Puiatti ${ }^{3}$, Paulo Roberto Cecon 4 , Aline da Silva Bhering 5 , \\ Geovani do Carmo Copati da Silva ${ }^{6}$, João Nacir Colombo
}

\begin{abstract}
RESUMO
A consorciação de culturas é um sistema de cultivo que tem como objetivos principais alcançar alta produtividade por unidade de área e promover a sustentabilidade do sistema de produção. Objetivou-se com este trabalho avaliar a viabilidade agronômica e a rentabilidade econômica do consórcio do taro (Colocasia esculenta) com feijão-vagem (Phaseolus vulgaris) de hábito de crescimento indeterminado. O experimento foi conduzido a campo, na horta do Departamento de Fitotecnia da Universidade Federal de Viçosa, no período de outubro/2011 a junho/2012. Constou de sete tratamentos resultantes de três cultivos consorciados do taro com feijão-vagem, estabelecidos aos 0,21 e 42 dias após o plantio do taro, e de quatro monoculturas, sendo três do feijão-vagem, estabelecidas nas mesmas épocas dos cultivos consorciados com o taro, e de uma do taro. O delineamento experimental utilizado foi o de blocos casualizados, com quatro repetições. Como material propagativo, utilizou-se o clone 'Japonês' e o cultivar de feijão-vagem 'Estrela' . A determinação dos custos de produção dos cultivos foi realizada com base no custo operacional de produção. Todos os sistemas consorciados foram agronomicamente viáveis, por apresentar Uso Eficiente da Terra (UET) acima de um. Dentre esses destacam-se os consórcios do feijão-vagem com o taro implementados a 0 e 21 dias após o plantio do taro, por proporcionarem maior renda líquida e vantagem monetária corrigida.
\end{abstract}

Palavras-chave: Colacasia esculenta, Phaseolus vulgaris, rentabilidade, produtividade, agricultura familiar.

\section{ABSTRACT}

\section{Agro-economic viability of intercropping taro with indeterminate snap beans in different cropping season}

Intercropping is a cultivation system that aims to achieve high productivity per unit area and promote the sustainability of the production system. The objective of this work was to evaluate the agronomic viability and economic yield of taro (Colocasia esculenta) intercropped (additive association) with snap beans (Phaseolus vulgaris) of indeterminate growth habit. The experiment was conducted in the vegetable experimental field of the Universidade Federal de Viçosa, from October 2011 to June 2012. The experiment consisted of seven treatments represented by three intercrops of taro with snap beans set up at 0,21, and 42 days after the taro planting, and four monocroppings,

Recebido para publicação em 26/03/2013 e aprovado em 06/09/2013.

${ }^{1}$ Parte da Dissertação de Mestrado da primeira autora.

${ }^{2}$ Engenheira-Agrônoma. Departamento de Fitotecnia, Universidade Federal de Viçosa, Campus Viçosa, Avenida Peter Henry Rolfs, s/n, 36570-000, Viçosa, Minas Gerais, Brasil. jani_cassia@yahoo.com.br (autora para correspondência).

${ }^{3}$ Engenheiro-Agrônomo, Doutor. Departamento de Fitotecnia, Universidade Federal de Viçosa, Campus Viçosa, Avenida Peter Henry Rolfs, s/n, 36570-000, Viçosa, Minas Gerais, Brasil. mpuiatti@ufv.br

${ }^{4}$ Engenheiro-Agrônomo, Doutor. Departamento de Estatística, Universidade Federal de Viçosa, Campus Viçosa, Avenida Peter Henry Rolfs, s/n, 36570-000, Viçosa, Minas Gerais, Brasil. cecon@ufv.br

${ }^{5}$ Engenheira-Agrônoma. Departamento de Fitotecnia, Universidade Federal de Viçosa, Campus Viçosa, Avenida Peter Henry Rolfs, s/n, 36570-000, Viçosa, Minas Gerais, Brasil. alinebhering@hotmail.com

${ }^{6}$ Graduanda em Agronomia. Universidade Federal de Viçosa, Campus Viçosa, Avenida Peter Henry Rolfs, s/n, 36570-000, Viçosa, Minas Gerais, Brasil. geovani.silva@ufv.br ${ }^{7}$ Engenheiro-Agrônomo, Mestre. Departamento de Fitotecnia, Universidade Federal de Viçosa, Campus Viçosa, Avenida Peter Henry Rolfs, s/n, 36570-000, Viçosa, Minas Gerais, Brasil. joaonacirc@yahoo.com.br 
represented by three of snap bean established in the same times of the intercropping with taro and taro monocropping. The experiments were arranged in a randomized block design with four replications. The propagative material used was the taro clone 'Japonês' and seeds of snap bean variety 'Estrela'. The determination of crop production costs was based on the operational production costs. All the intercropping systems were agronomically viable showing Land Use Efficiency (LUE) above 1. The intercropp snap bean with taro implemented at 0 and 21 days after the taro planting showed the best results for providing the highest economic yield.

Key words: Colacasia esculenta, Phaseolus vulgaris, profitability, yield, family farming.

\section{INTRODUÇÃO}

A produção de hortaliças é uma atividade quase sempre presente em pequenas propriedades familiar, seja como atividade de subsistência ou com a finalidade de comercialização do excedente agrícola em pequena escala. A pequena propriedade rural é caracterizada pela limitação de área, possui produção agrícola diversificada e preocupação com a preservação dos recursos naturais e a qualidade de vida (Montezano \& Peil, 2006). Em razão disso, faz-se necessária a geração e/ou domínio de tecnologias que aumentem o aproveitamento da área disponível e diminuem os danos ao ambiente. Dentre essas tecnologias, o cultivo consorciado de hortaliças destacase com grande potencial (Oliveira et al., 2004).

Nos cultivos consorciados, duas ou mais culturas, com diferentes ciclos e arquiteturas vegetativas, são exploradas concomitantemente na mesma área. Ressalte-se que as culturas não são necessariamente semeadas ou plantadas ao mesmo tempo, mas durante apreciável parte de seus períodos vegetativos há simultaneidade, forçando a interação entre elas (Vieira, 1998). São muitos os benefícios dos sistemas consorciados, dentre eles cita-se: estabilidade da produção em diferentes estações; maior retorno econômico; diversificação do produto colhido; e aproveitamento da terra, água, dos insumos agrícolas e da mão de obra (Cecílio Filho \& May, 2002; Montezano \& Peil, 2006; Gliessman, 2004), com destaque para a possibilidade de maior rendimento por unidade de área em razão do aumento ou compensação da produtividade das culturas componentes do consórcio (Gliessman, 2004).

A cultura do taro apresenta aspectos considerados bastante positivos em termos de cultivo alternativo, como rusticidade em relação a fatores ambientais e biológicos adversos e, por apresentar ciclo longo (cerca de nove meses), torna-se uma cultura bastante interessante para o cultivo consorciado. Embora o taro apresente características morfológicas e fisiológicas que permitem a associação com outras espécies, pesquisas envolvendo especificamente consórcio do taro com outras hortaliças são relativamente poucas, dentre as quais são citadas: taro com alface (Heredia Zárate et al., 2005; 2007a); taro com chicória (Heredia Zárate et al., 2007b); taro com cenoura e alface (Heredia Zárate et al., 2006); e taro com milho doce (Puiatti et al., 2000). Há trabalhos envolvendo uso de adubos verdes no cultivo do taro, mas em cultivo intercalar com guandu (Oliveira et al., 2006) ou crotalária (Oliveira et al., 2004; 2007) e tolerância das plantas ao sombreamento artificial (Gondim et al., 2007).

Devido às características que a cultura do taro possui em termos de morfologia da planta, espaçamento utilizado, ciclo cultural, exigências climáticas e tolerância ao sombreamento parcial (Gondim et al., 2007; Puiatti et al., 2000), a associação do taro com a cultura do feijão-vagem indeterminado seria potencialmente vantajosa e merecedora de pesquisa. O feijão-vagem (Phaseolus vulgaris L.) é uma hortaliça rica em fibras e tem apreciáveis quantidades de vitaminas e de minerais (Pinto et al., 2007). Os cultivares de hábito indeterminado iniciam a colheita por volta de 40 dias, podendo colher vagens durante cerca de 30 dias. A associação do feijão-vagem indeterminado com o taro permitiria a entrada antecipada de recursos para o produtor rural, compensando o longo ciclo cultural do taro. Todavia, a produtividade das culturas em consórcio e a viabilidade econômica desse sistema de cultivo são dependentes do período de convivência das espécies em consorciação, determinado pela época de estabelecimento do consórcio.

Face ao exposto, objetivou-se com este trabalho avaliar a viabilidade agronômica e econômica do consórcio do taro com feijão-vagem em três épocas de instalação dos consórcios.

\section{MATERIAL E MÉTODOS}

O trabalho foi desenvolvido a campo, na horta da Universidade Federal de Viçosa (UFV), em Viçosa-MG, no período de 30/09/2011 a 30/06/2012. O município de Viçosa está a 650 m de altitude, $20^{\circ} 45^{\prime} 47^{\prime \prime} \mathrm{LS}$ e $42^{\circ} 49^{\prime} 13^{\prime \prime} \mathrm{LW}$. De acordo com a classificação de Köppen, apresenta clima tipo "Cwa"(clima subtropical úmido), com médias anuais de $1.341 \mathrm{~mm}$ de precipitação e temperaturas máxima e mínima de $21,6^{\circ} \mathrm{C}$ e de $14{ }^{\circ} \mathrm{C}$, respectivamente. 
O solo da área experimental é classificado como Argissolo Vermelho-Amarelo Cambissólico, textura Argilosa (Embrapa, 2006), cuja amostragem, na profundidade de $0-20 \mathrm{~cm}$, revelou os seguintes resultados: $\mathrm{pH}_{\text {(água) }}=6,4$; $\mathrm{P}=180$ e $\mathrm{K}=102 \mathrm{mg} \mathrm{dm}^{-3} ; \mathrm{Ca}^{2+}=5,0 ; \mathrm{Mg}^{2+}=0,7 \mathrm{e} \mathrm{Al}^{3+}=0,0$ $\mathrm{cmol}_{\mathrm{c}} \mathrm{dm}^{-3} ; \mathrm{B}=0,7 ; \mathrm{Fe}=188 ; \mathrm{Mn}=104,4 ; \mathrm{Zn}=12 \mathrm{e} \mathrm{Cu}=3,5$ $\mathrm{mg} \mathrm{dm}{ }^{-3} ; \mathrm{M} . \mathrm{O}=2,7 \mathrm{dag} \mathrm{kg}^{-1} ;(\mathrm{H}+\mathrm{Al})=2,48 \mathrm{SB}=5,10$; $\mathrm{CTC}_{(\mathrm{t})}=9,05 \mathrm{e} \mathrm{CTC}_{(\mathrm{T})}=8,11 \mathrm{cmol} \mathrm{dm}_{\mathrm{c}}^{-3} ; \mathrm{V}=73 \%$; e P-rem $=$ $29,9 \mathrm{mg} \mathrm{L}^{-1}$. As análises foram realizadas segundo procedimento descrito por Embrapa (1999).

Os tratamentos, em número de sete, consistiram da consorciação das culturas do taro e feijão-vagem, em associação aditiva, em três épocas de implantação dos consórcios, com os respectivos cultivos solteiros, conforme Tabela 1. Utilizou-se o delineamento experimental em blocos casualizados, com quatro repetições. As parcelas foram constituídas de quatro linhas de $2,4 \mathrm{~m}$ de comprimento, espaçadas de 1,0 m com, respectivamente, oito plantas de taro e sete de feijão-vagem por linha.

$\mathrm{O}$ plantio do taro foi realizado em sulcos abertos à profundidade de 0,12 m, onde foram colocadas as mudas e cobertas com solo. Foram utilizados rizomas filho de taro 'Japonês' (BGH 5925) com massa média de 60 g, obtidos do Banco de Germoplasma de Hortaliças da UFV. As sementes de feijão-vagem 'Estrela', do grupo macarrão, no cultivo solteiro, foram depositadas em sulcos abertos à profundidade de 0,05 m; quando em consórcio, foram depositadas em covas de cerca de $0,05 \mathrm{~m}$ de profundidade entre as plantas de taro. Aos 15 dias após a emergência procedeu-se o desbaste, deixando-se apenas uma planta por cova.

A fertilização do solo para as culturas foi com base nas análises química e física do solo e nas recomendações para as culturas, conforme Ribeiro et al. (1999). Portanto, os tratamentos em consórcio receberam as adubações recomendadas para ambas as culturas, conforme Cecílio Filho et al. (2008). Os demais tratos culturais foram de acordo com as recomendações técnicas para as culturas do taro (Puiatti, 2002) e do feijão-vagem (Pinto et al., 2007), respectivamente.

As plantas de feijão-vagem foram tutoradas individualmente, na vertical, com auxílio de bambu fincado ao solo. O controle das plantas daninhas foi realizado com o auxílio de enxada aos 25, 62, 83, 115 e 203 dias após o plantio (DAP). Na ausência de chuvas e até 30 dias antes da colheita do taro, os cultivos receberam irrigações semanais, por aspersão, aplicando-se em cada irrigação lâmina de água suficiente para atender à demanda das culturas.

Em razão do feijão-vagem ser de hábito de crescimento indeterminado, as colheitas foram parceladas, realizadas três vezes por semana e duraram cerca de 30 dias para cada plantio (Tabela 1). Após cada colheita, as vagens foram selecionadas e pesadas. Na seleção, foram consideradas impróprias para comercialização as vagens cur- vas, malformadas (incidência de cavidade interocular), doentes e com perfurações provocadas por insetos. Determinaram-se: rendimento de matéria fresca de vagens comerciais e não comerciais, diâmetro e comprimento de vagens, número total de vagens, número de vagens comerciais e rendimento total de vagens.

Aos 90, 120, 150 e 180 dias após o plantio foram realizadas estimativas do Índice de Área foliar (IAF) e do coeficiente de extinção de luz (índice k) com auxílio de um ceptômetro AccuPAR modelo LP-80. Aos 274 DAP do taro, 10 plantas por repetição, dentro da parcela útil, foram colhidas e avaliadas quanto à produção de rizomas (massa de matéria fresca e número). Os rizomas mãe foram separados e os rizomas filhos, classificados com base no diâmetro transversal, de acordo com Puiatti et al. (2000), nas classes filho grande (FG), médio (FM), pequeno (FP) e refugo (REF). A produtividade total consistiu do somatório das produtividades de rizomas mãe e de todas as classes de rizomas filho. Considerou-se comerciável o somatório das classes FG + FM + FP.

Os indicadores agroeconômicos usados para medir a eficiência dos sistemas consorciados foram, conforme Beltrão et al. (1984), índice de uso eficiente da terra (UET), renda bruta $(\mathrm{RB})$; renda líquida $(\mathrm{RL})$, vantagem monetária (VM) e vantagem monetária corrigida (VMc). O índice UET é dado pela expressão: UET $=\left(\mathrm{I}_{\text {taro }} / \mathrm{S}_{\text {taro }}\right)+\left(\mathrm{I}_{\text {feijão-vagem }} /\right.$ $\left.\mathrm{S}_{\text {feijão-vagem }}\right)$, em que I e $\mathrm{S}$ representam as produtividades dos sistemas consorciado e solteiro de cada cultura.

A renda bruta (RB) foi obtida multiplicando-se a produtividade da cultura em cada tratamento pelo valor do produto pago ao produtor. Para o feijão-vagem, fez-se a média dos preços durante os meses de colheita, enquanto para o taro foram utilizados os preços do produto no dia da colheita. Os valores pagos pelos produtos no mês da colheita do taro e do feijão-vagem foram: $\mathrm{R} \$ 0,81 ; 0,79$; e 0,81 para o primeiro, segundo e terceiro plantios de feijão-vagem, respectivamente. Para o taro o valor pago foi de $\mathrm{R} \$ 1,15 / \mathrm{kg}$ (Ceasa-MG, 2012).

A renda líquida (RL) foi calculada subtraindo-se da renda bruta os custos de produção provenientes de insumos mais serviços. Esses custos (C) foram calculados para cada tratamento, levando-se em conta os coeficientes de custo de insumos e os serviços utilizados em um hectare de taro e feijão-vagem em nível experimental. A vantagem monetária e a vantagem monetária corrigida foram obtidas pelas seguintes expressões: $\mathrm{VM}=\mathrm{RB} \times(\mathrm{UET}-1) / \mathrm{UET}$ e VMc = RL x (UET-1)/UET (Beltrão et al., 1984).

Os dados obtidos foram submetidos à análise de variância. As médias dos tratamentos foram comparadas entre si pelo teste de Tukey e comparadas ao controle pelo teste de Dunnett. Os contrastes de interesse foram comparados pelo teste $\mathrm{F}$, todos a $5 \%$ de probabilidade, usando o programa SAEG 9.1 (SAEG, 2007). 


\section{RESULTADOS E DISCUSSÃO}

\section{Produção do taro}

Houve diferenças entre os tratamentos para produção de rizomas total, comercial, filho grande e refugo (Tabela 2). Comparado ao controle, a associação do feijão-vagem com o taro aos 42 DAP do taro proporcionou maiores rendimentos de rizomas total e filho grande e menor rendimento de rizoma refugo. Essa associação também proporcionou maiores rendimentos de rizomas total, comercial e filho grande e menor rendimento de rizoma refugo comparado ao consórcio implantado ao 0 DAP do taro.

Observa-se que a associação do feijão-vagem com o taro a 0 DAP do taro foi a que proporcionou os menores valores de rendimento de rizomas, indicando que essa época da associação não permitiu que as plantas de taro expressassem o seu potencial produtivo em sua plenitude. A explicação para esses resultados está na competição por fatores de crescimento entre as duas culturas nos dois meses iniciais, que foi o período da associação com o feijão-vagem desse tratamento (Tabela 1). Na fase inicial do ciclo, o taro apresenta crescimento lento, com elevada taxa de crescimento das plantas entre 90 e 150 dias iniciais (Puiatti et al., 1992). Portanto, nessa fase inicial de crescimento ainda lento das plantas de taro as plantas de feijão-vagem, por apresentarem crescimento inicial mais elevado que as de taro, cresceram mais rapidamente, promovendo maior competição por fatores de crescimento.

Por sua vez, a associação do feijão-vagem aos 42 DAP do taro foi benéfica à cultura do taro, proporcionando rendimento, 1,32 vez maior que o controle para RM, de 1,19 vez para RT, de 1,24 vez para RC e de 2,14 vezes para rizomas FG. Além disso, enquanto no cultivo solteiro a produção de RC correspondeu a cerca de $57 \%$ da produção de RT e a de FG cerca de $28 \%$ da produção de RC, na associação aos 42 DAP a produção de RC foi responsável por cerca de $60 \%$ da de RT e a de FG a cerca de $48 \%$ da de RC. Portanto, a associação do feijão-vagem com taro aos
42 DAP proporcionou maior percentual de rizomas comerciais e de filho grande, o último com maiores cotações de mercado, além de menor produção de rizomas refugo.

Os arranjos espaciais são importantes fatores de manejo a serem manipulados para melhorar o uso de recursos e a eficiência da prática do consórcio em hortaliças (Bezerra Neto et al., 2003). Todavia, a época da implantação dessas associações também é fundamental. Embora em sistemas de culturas múltiplas, onde encontram-se raízes que exploram o solo a diferentes profundidades, ou onde as folhas podem responder diferencialmente à competição por luz (Harder et al., 2005), há momentos em que as culturas competem por esses fatores em mesmo grau.

A associação do taro com outras olerícolas tem mostrado resultados diversos. Em cultivo de taro 'Chinês' solteiro e consorciado com chicória, Heredia Zarate et al. (2007) observaram maior produção comercial do taro no cultivo solteiro. Por outro lado, no consórcio do taro 'Chinês' com alface 'Quatro Estações', Heredia Zarate et al. (2006) encontraram produção comercial superior no cultivo consorciado.

Os rendimentos de rizomas obtidos neste trabalho estão bem acima dos encontrados por Heredia Zarate $e t$ al. (2006) com taro 'Chinês' em Dourados-MS, que verificaram produtividades de 5,11 tha $^{-1}$ no cultivo solteiro e de $2,77 \mathrm{t} \mathrm{ha}^{-1}$ no cultivo consorciado com cenoura 'Brasília' e alface 'Quatro Estações', respectivamente. Além das culturas e épocas de associação, condições edafoclimáticas distintas podem levar a resultados contrastantes.

Apesar da maioria das espécies da família Araceae serem consideradas plantas de sombra (Rubatzky \& Yamagushi, 1997), o sombreamento das plantas de taro proporcionado pelo feijão-vagem no tratamento de consórcio implementado a 0 DAP, pode ter influenciado nas menores produtividades observadas para o taro. Essa competição não foi verificada em intensidade tão elevada nas associações aos 21 e 42 DAP do taro, em razão das plantas de taro já estarem em estádio fenológico mais avan-

Tabela 1. Tratamentos utilizados no experimento com as respectivas datas de plantio e de colheita das culturas e a época de implantação do consórcio do feijão-vagem com a cultura do taro e a respectiva cultura solteira do feijão-vagem

\begin{tabular}{|c|c|c|c|c|c|}
\hline \multirow[t]{3}{*}{ Tratamentos } & \multicolumn{5}{|c|}{ Cultura/período de cultivo } \\
\hline & \multicolumn{2}{|c|}{ Taro } & \multicolumn{3}{|c|}{ Feijão-vagem } \\
\hline & Plantio & Colheita & Plantio & Colheita & $\mathbf{E F V}^{\prime 1}$ \\
\hline 1-Taro Solteiro & $30 / 09 / 2011$ & $30 / 06 / 2012$ & \multicolumn{2}{|c|}{ Ausente } & \\
\hline 2-Taro Consorcio & $30 / 09 / 2011$ & $30 / 06 / 2012$ & $30 / 09 / 2011$ & $27 / 11 / 2011$ & 0 \\
\hline 3-Taro Consorcio & $30 / 09 / 2011$ & $30 / 06 / 2012$ & $21 / 10 / 2011$ & $11 / 01 / 2012$ & 21 \\
\hline 4- Taro Consorcio & $30 / 09 / 2011$ & $30 / 06 / 2012$ & $11 / 11 / 2011$ & $18 / 01 / 2012$ & 42 \\
\hline 5- Feijão Solteiro & \multicolumn{2}{|c|}{ Ausente } & $30 / 09 / 2011$ & $27 / 11 / 2011$ & 0 \\
\hline 6- Feijão Solteiro & \multicolumn{2}{|c|}{ Ausente } & $21 / 10 / 2011$ & $11 / 01 / 2012$ & 21 \\
\hline 7- Feijão Solteiro & \multicolumn{2}{|c|}{ Ausente } & $11 / 11 / 2011$ & $18 / 01 / 2012$ & 42 \\
\hline
\end{tabular}

$\mathrm{EFV}^{1 /}=$ Época de implantação do feijão-vagem (em dias após o plantio do taro), em consórcio com taro e respectivo cultivo solteiro do feijão-vagem. 
çado quando da implantação dos consórcios. Esses resultados evidenciam que as plantas de taro necessitam de um período inicial de até 21 DAP isento de competição para que as plantas possam prosseguir o seu desenvolvimento posterior de maneira normal.

\section{Produção do feijão-vagem}

Os valores das características avaliadas na cultura do feijão-vagem consorciado foram inferiores aos do cultivo solteiro, com valores negativos em quase todos os contrastes, exceto para comprimento de vagem (Y1 e Y2), produção não comercial (Y1) e diâmetro de vagens (Y3), (Tabela 3). Esses resultados evidenciam que as plantas de feijão-vagem consorciadas sofreram competição das plantas de taro com menores valores das características CVA no consórcio Y3; DVA nos consórcios Y1 e Y2; NVP, PT, PC, MFPA e MSPA nos consórcios nas três épocas (Y1, Y2 e Y3); e de PNC nos consórcios Y2 e Y3. O menor rendimento do feijão-vagem está associado à competição que naturalmente ocorre em cultivos com associação aditiva, como no presente trabalho.

As plantas de feijão-vagem em consórcio sofreram competição das plantas de taro por fatores de crescimento, como pode ser visualizado pela massa de matéria fresca da planta (Tabela 3). Embora essa competição tenha afetado todas as características avaliadas, o número de vagens por planta foi o mais afetado, o que refletiu nas produções total, comercial e não comercial de vagens. Todavia, apesar de o consórcio ter provocado impacto sobre o desempenho do feijão-vagem, não inviabilizou a obtenção de vagens com padrão comercial, de acordo com o Ceasa-MG (Ceasa-MG, 2012).

Há carência de pesquisas sobre consórcio de feijãovagem com outras olerícolas. Souza et al. (2007) observaram maior produção do feijão-vagem em cultivo solteiro ao avaliar o rendimento agronômico do consórcio de pimentão com feijão-vagem arbustivo em sistema orgânico. Em sistemas de consórcio milho e feijão-comum, Costa e Silva (2008) observaram que as plantas de feijão no sistema solteiro produziram quase o dobro de vagens por planta comparada ao cultivo consorciado, evidenciando que a cultura do milho também interferiu na produção de vagens. Todavia, Costa et al., (1997) verificaram período das águas que as plantas de feijão desenvolveram o mesmo número de vagens nos sistemas solteiro e consorciado. Por outro lado, Hussein et al. (2005) constataram que o rendimento total e o comprimento de vagens não foram afetados pela consorciação do feijão-vagem com alface e cebolinha de folha, que são plantas de porte menor que do feijão-vagem.

\section{Características morfológicas das plantas}

Aos 90 dias todos os tratamentos em consorcio e aos 120 dias o consórcio 0 DAP do taro apresentaram valores de IAF menores que do controle (Tabela 4). Também aos 90 dias, os consórcios 0 e 21 DAP do taro e aos 120 dias o consórcio 0 DAP do taro apresentaram menores valores de k que a monocultura do taro. Esses resultados evidenciam que as plantas de taro tiveram o seu crescimento afetado pela competição com as plantas do feijão-vagem.

O hábito de crescimento indeterminado das plantas de feijão-vagem que alcançaram a altura do tutor $(2,0 \mathrm{~m})$ ocasionou sombreamento das plantas de taro, resultando em menores valores de IAF e de k nas primeiras avaliações devido à menor área foliar, especialmente das plantas de taro. O efeito negativo da competição foi mais pronunciado no consórcio implementado mais precocemente (0 DAP), conforme demonstrado pelos menores valores de IAF e de k na avaliação realizada aos 120 dias (Tabela 4); ou seja, 60 dias após a retirada das plantas de feijãovagem (Tabela 1). A menor produção de classes de rizomas de taro verificada nesse consórcio (Tabela 2) certamente se deve ao efeito negativo da competição sobre o IAF das plantas do taro.

Resultados semelhantes foram obtidos por Godim et al. (2007) avaliando o crescimento, a partição de fotoassimilados e produção de rizomas em taro cultivado sob sombreamento artificial, os quais observaram que o máximo de IAF do taro ocorreu entre 90 e 120 DAP. Aárea foliar é importante atributo fisiológico associada positivamente com a produção de rizomas (Puiatti et al., 2000), e a luz é fator determinante da produtividade em taro, pois, além da produção de biomassa, interfere na morfologia,

Tabela 2. Valores médios para rendimentos em massa de matéria fresca de rizomas mãe (RM), total (RT), comercial (RC), filho grande (FG), filho médio (FM), filho pequeno (FP), filho refugo (REF) e número de rizomas filho comerciais por planta (NFCP)

\begin{tabular}{|c|c|c|c|c|c|c|c|c|}
\hline \multirow[t]{2}{*}{ Tratamento } & $\mathbf{R M}$ & RT & $\mathbf{R C}$ & FG & FM & FP & REF & \multirow{2}{*}{$\frac{\text { NFCP }}{\text { ud/planta }}$} \\
\hline & \multicolumn{7}{|c|}{ tha $^{-1}$} & \\
\hline Monocultura Taro & $14,05 \mathrm{a}$ & $50,30 \mathrm{ab}$ & $28,91 \mathrm{ab}$ & $8,10 \mathrm{~b}$ & $13,47 \mathrm{a}$ & $7,33 \mathrm{a}$ & $7,33 \mathrm{a}$ & $12,30 \mathrm{a}$ \\
\hline Consórcio - 0 DAP & $15,49 \mathrm{a}$ & $44,84 \mathrm{~b}$ & $22,58 \quad b$ & $5,81 \mathrm{~b}$ & $11,24 \mathrm{a}$ & $5,45 \mathrm{a}$ & $6,76 \mathrm{a}$ & $10,25 \mathrm{a}$ \\
\hline Consórcio - 21 DAP & $15,95 \mathrm{a}$ & $57,13 \mathrm{ab}$ & $33,31 \mathrm{a}$ & $11,70 \mathrm{ab}$ & $15,21 \mathrm{a}$ & $6,36 \mathrm{a}$ & $7,87 \mathrm{a}$ & $13,46 \mathrm{a}$ \\
\hline Consórcio - 42 DAP & $18,51 \mathrm{a}$ & $59,75 \mathrm{a}^{*}$ & $35,83 \mathrm{a}$ & $17,31 \mathrm{a}^{*}$ & $13,50 \mathrm{a}$ & $5,01 \mathrm{a}$ & $5,40 \mathrm{~b}^{*}$ & $11,96 \mathrm{a}$ \\
\hline C.V (\%) & 26,28 & 10,65 & 13,53 & 35,77 & 27,07 & 22,41 & 19,60 & 14,88 \\
\hline
\end{tabular}

Médias, nas colunas, seguidas de pelo menos uma mesma letra não diferem entre si pelo teste de Tukey a 5\% de probabilidade; médias, nas colunas, seguidas de asterisco $(*)$, diferem do controle ao nível de $5 \%$ de probabilidade. 
exportação e distribuição de assimilados (Puiatti et al., 2000). Segundo Godim et al. (2007), quando as plantas de taro são submetidas a um intenso sombreamento nas primeiras fases de expansão da lâmina foliar e à medida que a restrição de luz for se acentuando com o ciclo devido ao autossombreamento, as plantas passam a investir no crescimento do pecíolo à procura de luz, sobretudo aquelas sob maior restrição de luz. Os dados de menores valores de IAF encontrados nas avaliações realizadas aos 90 e 120 dias, sobretudo no consórcio implementado ao 0 DAP do taro, evidenciam esse fenômeno.

O coeficiente de extinção de luz (k) apresentou comportamento semelhante ao do IAF (Tabela 4). O k está ligado à disposição das folhas e ao ângulo de inclinação das folhas que, juntamente com o IAF, fornece uma indicação da eficiência das plantas em interceptar a radiação solar (Bernardes et al., 2011). Estudos com esse enfoque fornecem importantes respostas sobre a utilização da radiação solar pelas plantas; entretanto, para a cultura do taro poucos são os estudos disponíveis nesse contexto. Bernardes et al. (2011) obtiveram k para monocultura do taro variando de 0,44 a 0,99. Brown \& Blaser (1968) relatam valores de coeficiente de extinção de luminosa variando de 0,4 a 0,7 para espécies de folhas eretas como o azevém perene e de 0,8 a 1,0 para espécies com folhas mais horizontais como alfafa. No presente trabalho, o k variou de 0,31 a 0,49. Esses valores de $\mathrm{k}$, relativamente baixos, são devidos à arquitetura ligeiramente ereta das folhas das plantas de taro.

\section{Indicadores agroeconômicos}

Na Tabela 5 encontram-se os indicadores agroeconômicos dos sistemas consorciados de taro com feijão-vagem. De modo geral, maiores eficiências biológicas e eco- nômicas foram observadas nos cultivos consorciados. Comparados ao controle, os consórcios implantados aos 0, 21 e 42 DAP do taro apresentaram índice de uso da terra (UET), respectivamente, de 63\%,86\% e $128 \%$ maior; a renda bruta foi $81 \%, 72 \%$ e $38 \%$ maior e a renda líquida de $92 \%, 80 \%$ e $32 \%$ maior.

Portanto, melhor aproveitamento dos fatores ambientais disponíveis se deu nos sistemas consorciados em relação ao sistema solteiro, uma vez que os índices de uso da terra (UETs) foram maiores que 1 (a unidade), variando de 63 a 128\%. Isso significa que são necessários de 63 a $128 \%$ a mais de área para que as culturas em plantio solteiro produzam o equivalente à produção dessas consorciadas em um hectare.

Os valores obtidos para a UETs e para a renda bruta são coerentes com as citações de Sullivan (2001), Salvador $e t$ al. (2003) e Harder et al. (2005) de que o aumento da produtividade por unidade de área é uma das razões mais importantes para se cultivar duas ou mais culturas no sistema de consorciação. Esse sistema permite melhor aproveitamento da terra e de outros recursos disponíveis, resultando, na maioria das vezes, em maior rendimento econômico.

Resultados similares foram encontrados por Heredia Zárate et al. (2005), que obtiveram valores de UET e renda bruta superiores nos cultivos consorciados de dois cultivares de taro com alface em relação ao cultivo solteiro. Heredia Zárate (2006) obteve UETs de $6 \%$ e de $83 \%$ no consórcio de taro com cenoura e taro com alface, respectivamente.

Nos cultivos consorciados implantados especialmente aos 0 e 21 DAP foi constatada grande participação da cultura do feijão-vagem na composição dos índices avaliados. Apesar do alto índice de UET no consórcio implantado aos 42 DAP, esse apresentou a menor renda bruta,

Tabela 3. Valores médios observados e contrastes entre cultivos consorciados e solteiros de feijão-vagem, nas três épocas de associação (Y1, Y2 e Y3), das características comprimento (CVA) e diâmetro de vagem (DVA), número de vagens por planta (NVP), produções total (PT), comercial (PC) e não comercial (PNC) de vagens e produções de massa de matérias fresca (MFPA) e seca da parte aérea (MSPA) das plantas após colheita de todas as vagens

\begin{tabular}{|c|c|c|c|c|c|c|c|c|c|}
\hline \multirow{2}{*}{\multicolumn{2}{|c|}{$\begin{array}{l}\text { Contrastes } \\
\text { Tratamentos }\end{array}$}} & CVA & DVA & NVP & PT & PC & \multirow{2}{*}{$\frac{\text { PNC }}{\text { kg ha }^{-1}}$} & MFPA & MSPA \\
\hline & & \multicolumn{2}{|c|}{ cm } & ud & \multicolumn{2}{|c|}{ t ha-1 } & & \multicolumn{2}{|c|}{ ha $^{-1}$} \\
\hline & 2 & 13,56 & 0,90 & 145,75 & 29,59 & 29,3 & 196,66 & 19,52 & 4,75 \\
\hline & 5 & 13,55 & 0,91 & 170,62 & 35,46 & 35,25 & 191,66 & 23,29 & 5,12 \\
\hline Y1 & & $0,01^{\mathrm{NS}}$ & $-0,01^{\mathrm{NS}}$ & $-24,87^{*}$ & - 5,87* & $-5,95^{*}$ & $5,00^{\mathrm{NS}}$ & $-3,77^{\mathrm{NS}}$ & $-0,37^{\mathrm{NS}}$ \\
\hline & 3 & 13,86 & 0,89 & 84,30 & 16,87 & 16,69 & 181,66 & 13,34 & 3,25 \\
\hline & 6 & 13,82 & 0,90 & 120,90 & 25,41 & 25,20 & 207,50 & 18,26 & 4,01 \\
\hline Y2 & & $0,04^{\mathrm{NS}}$ & $-0,01^{\mathrm{NS}}$ & $-36,60 * *$ & $-8,54 * *$ & $-8,51 * *$ & $-25,84^{\mathrm{NS}}$ & $-4,92^{\mathrm{NS}}$ & $-0,76^{\mathrm{NS}}$ \\
\hline & 4 & 12,59 & 0,85 & 22,22 & 3,71 & 3,61 & 98,33 & 4,22 & 1,03 \\
\hline & 7 & 12,83 & 0,81 & 30,45 & 4,93 & 4,73 & 200,83 & 7,97 & 1,75 \\
\hline Y3 & & $-0,24^{\mathrm{NS}}$ & $0,04 * *$ & $-8,23^{\mathrm{NS}}$ & $-1,22^{\mathrm{NS}}$ & $-1,12^{\mathrm{NS}}$ & $-102,50 * *$ & $-3,75^{\mathrm{NS}}$ & $-0,72^{\mathrm{NS}}$ \\
\hline
\end{tabular}

Ns; **; *: respectivamente não significativo e significativo a $1 \%$ e $5 \%$ de probabilidade pelo teste $\mathrm{F}$.

Y1 - Feijão-vagem consorciado com o taro a 0 DAP vs. Feijão-vagem solteiro a 0 DAP.

Y2 - Feijão-vagem consorciado com o taro aos 21 DAP vs. Feijão-vagem solteiro aos 21 DAP.

Y3 - Feijão-vagem consorciado com o taro aos 42 DAP vs. Feijão-vagem solteiro aos 42 DAP. 
Tabela 4. Valores médios do índice de área foliar e do coeficiente de extinção de luz (k) dos cultivos aos 90, 120, 150 e 180 dias após o plantio do taro, medido nos sistemas monocultivo de taro e em três épocas de associação (consórcios) do taro com feijão-vagem

\begin{tabular}{|c|c|c|c|c|}
\hline \multirow[b]{2}{*}{ Tratamentos } & \multicolumn{4}{|c|}{ Dias após plantio do taro } \\
\hline & 90 & 120 & 150 & 180 \\
\hline & \multicolumn{4}{|c|}{ Índice de área foliar } \\
\hline Monocultura taro & $6,91 \mathrm{a}$ & $6,21 \mathrm{a}$ & $4,35 \mathrm{a}$ & $2,58 \mathrm{a}$ \\
\hline Consórcio - 0 DAP & $2,90 \quad c^{*}$ & $2,96 b^{*}$ & $3,64 \mathrm{a}$ & $2,76 a$ \\
\hline Consórcio - 21 DAP & $4,27 \mathrm{bc}^{*}$ & $5,11 \mathrm{a}$ & $3,97 \mathrm{a}$ & $3,48 \mathrm{a}$ \\
\hline \multirow[t]{2}{*}{ Consórcio - 42 DAP } & $5,41 \mathrm{ab}^{*}$ & $5,27 \mathrm{a}$ & $4,63 \mathrm{a}$ & $3,10 \mathrm{a}$ \\
\hline & \multicolumn{4}{|c|}{ Coeficiente de extinção de luz (k) } \\
\hline Monocultura do taro & $0,47 \mathrm{a}$ & $0,39 \mathrm{a}$ & $0,46 \mathrm{a}$ & $0,49 \mathrm{a}$ \\
\hline Consórcio - 0 DAP & $0,37 \mathrm{~b}^{*}$ & $0,31 a^{*}$ & $0,44 \mathrm{a}$ & $0,42 \mathrm{a}$ \\
\hline Consórcio - 21 DAP & $0,38 \mathrm{~b}^{*}$ & $0,40 \mathrm{a}$ & $0,40 \mathrm{a}$ & $0,46 \mathrm{a}$ \\
\hline Consórcio - 42 DAP & $0,43 \mathrm{ab}$ & $0,35 \mathrm{a}$ & $0,43 \mathrm{a}$ & $0,46 \mathrm{a}$ \\
\hline
\end{tabular}

Dentro de cada característica, médias, nas colunas, seguidas por pelo menos uma mesma letra não diferem entre si pelo teste de Tukey a 5\% de probabilidade; médias seguidas de asterisco (*) diferem do controle pelo teste de Dunnett a $5 \%$ de probabilidade.

Tabela 5. Indicadores agroeconômicos, Índice de Uso da Terra (UET), Renda Bruta (RB), Renda Líquida (RL), Vantagem Monetária (VM) e Vantagem Monetária corrigida (VMc)

\begin{tabular}{|c|c|c|c|c|c|}
\hline Sistemas Consorciados & UET & $\mathbf{R B}\left(\mathbf{R} \$ \mathbf{h a}^{-1}\right)$ & $\mathbf{R L}\left(\mathbf{R} \$ \mathbf{h a}^{-1}\right)$ & VM $\left(\mathbf{R} \$ h^{-1}\right)$ & $\operatorname{VMc}\left(\mathbf{R} \$ h^{-1}\right)$ \\
\hline Monocultura taro & $1,00 \mathrm{c}$ & $23.132,00 \mathrm{~cd}$ & $16.579,00 \mathrm{~cd}$ & - & - \\
\hline Consorcio - 0 DAP & $1,63 \mathrm{~b}$ & $41.870,00 \mathrm{a}$ & $31.853,00 \mathrm{a}$ & $15.949,00 \mathrm{a}$ & $12.174,00 \mathrm{a}$ \\
\hline Consorcio - 21 DAP & $1,86 \mathrm{ab}$ & $39.833,00 \mathrm{a}$ & $29.816,00 \mathrm{ab}$ & $18.296,00 \mathrm{a}$ & $13.709,00 \mathrm{a}$ \\
\hline Consorcio - 42 DAP & $2,28 \mathrm{a}$ & $31.882,00 \mathrm{a}$ & $21.865,00 \mathrm{~cd}$ & $16.869,00 \mathrm{a}$ & $11.591,00 \mathrm{a}$ \\
\hline Monocultura feijão - 0 DAP & $1,00 \mathrm{c}$ & $28.557,00 \mathrm{bc}$ & $22.921,00 \mathrm{bc}$ & - & - \\
\hline Monocultura feijão - 21 DAP & $1,00 \mathrm{c}$ & $19.911,00 \mathrm{~d}$ & $14.275,00 \mathrm{~d}$ & - & - \\
\hline Monocultura feijão - 42 DAP & $1,00 \mathrm{c}$ & $4.213,00 \mathrm{e}$ & $-1.423,00 \mathrm{e}$ & - & - \\
\hline
\end{tabular}

*Médias, nas colunas, seguidas por pelo menos uma mesma letra não diferem entre si pelo teste de Tukey a $5 \%$ de probabilidade.

renda líquida e vantagem monetária corrigida dentre os consórcios, e a segunda pior em vantagem monetária. Nesse consórcio (42 DAP) houve a menor produtividade do feijão-vagem, que não foi decorrente somente da maior competição das plantas de taro devido à época da implantação da associação, mas foi ocasionada por intensas chuvas nesse período, que prejudicaram a cultura, como pode ser observado também pelo baixo rendimento no cultivodo feijão-vagem solteiro, o qual proporcionou renda líquida negativa (prejuízo).

\section{CONCLUSÃO}

Os consórcios do taro com feijão-vagem, nas três épocas implementadas, foram agronomicamente viáveis, considerando o UET e a renda bruta. Dentre esses destacamse os consórcios implementados a 0 e aos 21 dias após o plantio do taro, em razão da maior renda líquida e da vantagem monetária corrigida proporcionadas.

\section{AGRADECIMENTOS}

Ao CNPq pela concessão de bolsa de Mestrado ao primeiro autor, e a FAPEMIG pelo apoio financeiro.

\section{REFERÊNCIAS}

Beltrão NEM, Nobrega LB, Azevedo DMP \& Vieira DJ (1984) Comparação entre indicadores agroeconômicos de avaliação de agroecossistemas consorciados e solteiros envolvendo algodão 'upland' e feijão 'caupi'. Campina Grande, Embrapa-CNPA. 21 p. (Boletim de Pesquisa, 15).

Bernardes CO, Martins CAS, Lopes FS, Rocha MJR \& Xavier TMT (2011) Leaf área, leaf área index and light extintinction coeficiente for taro culture. Enciclopédia Biosfera, 12:01-09.

Bezerra Neto F, Andrade FV, Negreiros MZ \& Santos Júnior JS (2003) Desempenho agroeconômico do consórcio cenoura $\mathrm{x}$ alface lisa em dois sistemas de cultivo em faixa. Horticultura Brasileira, 21:635-641.

Brown RH \& Blaser RE (1968) Leaf area index in pasture growth. Herbage Abstracts, 38:01-09.

CEASA - Centrais de Abastecimento de Minas Gerais (2012) Disponível em: <http://minas.ceasa.mg.gov.br/detec/oferta_preco/ oferta_medio_prd/ofertas_medio_prd.php>. Acessado em: 07 de dezembro de 2012.

Cecílio Filho AB \& May A (2002) Produtividade das culturas de alface e rabanete em função da época de estabelecimento do consórcio. Horticultura Brasileira 20:501-504.

Cecílio Filho AB, Costa CC, Rezende BLA \& Leeuwen R (2008) Viabilidade produtiva e econômica do consórcio entre chicória e rúcula em função da época de plantio. Horticultura Brasileira, 26:316-320. 
Costa ASV \& Silva MB (2008) Sistemas de consórcio milho e feijão para a região do vale do Rio Doce, Minas Gerais. Ciências Agrotecnologias, 32:663-667.

Costa ASV, Vieira C, Cruz CD \& Cardoso AA (1997) Comportamento de variedades de feijão (phaseolus vulgaris L.) em dez ambientes compreendendo cinco sistemas de produção. Revista Ceres, 44:676-700

Embrapa - Empresa Brasileira de pesquisa Agropecuária (1999) Manual de análises químicas de solos, plantas e fertilizantes. Brasília, Embrapa Comunicação para Transferência de Tecnologia. 370p.

Embrapa - Empresa Brasileira de pesquisa Agropecuária (2006) Sistema brasileiro de classificação de solos. $2^{\mathrm{a}}$ ed. Rio de Janeiro, Embrapa. 306p.

Gliessman S (2004) Mixing broccoli and lettuce in an intercrop creates complementary patterns of resource use. In: Bley C (Ed.) Broccoli/Lettuce Intercropping in California, USA, (1999). Disponível em: <http://agroecology.org/cases/ broclettuce.htm>. Acessado em: 17 de junho de 2013.

Gondim ARO, Puiatti M, Cecon PR \& Finger FL (2007) Crescimento, partição de fotoassimilados e produção de rizomas em taro cultivado sob sombreamento artificial. Horticultura Brasileira, 25:418-428.

Harder WC, Heredia Zarate NA \& Vieira MC (2005) Produção e renda bruta de rúcula (Eruca Sativa Mill.) 'cultivada' e de almeirão (cichorium intybus L.) 'amarelo' em cultivo solteiro e consorciado. Ciência e agrotecnologia, 29:775-785.

Heredia Zárate NA, Vieira MC, Oliveira ACP \& Lima AA (2005) Produção e renda bruta de dois cultivares de taro, em cultivo solteiro e consorciado com alface. Semina: Ciências Agrárias, $26: 283-290$

Heredia Zárate NA, Vieira MC, Giuliani AR, Helmich M, Chiquito EG \& Amadori AH (2006) Taro 'Chinês' em cultivo solteiro e consorciado com cenoura 'Brasília' e alface 'Quatro Estações'. Horticultura Brasileira, 24:324-328.

Heredia Zárate NA, Vieira MC, Graciano JD, Helmich M, Gass RP, \& Souza CM (2007) Produção do taro chinês, em cultivo solteiro e consorciado com chicória. Ciências Agrotecnologia, 31:1558-1562.

Heredia Zárate NA, Vieira MC, Giuliani AR, Helmich M, Pontim BCA \& Pezzoni Filho JC (2007a) Produção e renda de taro Macaquinho, solteiro e consorciado com alface 'Salad Bowl', em solo com cobertura de cama-de-frango semidecomposta. Semina: Ciências Agrárias, 28:563-570.

Heredia Zárate NA, Vieira MC, Graciano JD, Helmich M, Gassi RP \& Souza CM (2007b) Produção do taro chinês, em cultivo solteiro e consorciado com chicória. Ciências Agrotecnologia, $31: 1558-1562$

Hussein SDA, Salman SR, Abdel Mawgoud AMR \& Ghoname AA (2005) Productivity, quality and profit of sole or intercropped green bean (Phaseolus Vulgaris L.) crop. Jornal of Agronomy, 4:151-155.

Montezano EM \& Peil RMN (2006) Sistema de consórcio na produção de hortaliças. Revista Brasileira Agrociência, 12:129132
Oliveira FL, Ribeiro RLD, Silva VV, Guerra JGM \& Almeida DL (2004) Desempenho do inhame (taro) em plantio direto e no consórcio com crotalária, sob manejo orgânico. Horticultura Brasileira, 22:638-641.

Oliveira FL, Guerra JGM, Junqueira RM, Silva EE, Oliveira FF, Espindola JAA, Almeida DL, Ribeiro RLD \& Urquiaga S (2006) Crescimento e produtividade do inhame cultivado entre faixas de guandu em sistema orgânico. Horticultura Brasileira, 24:5358 .

Oliveira FL, Guerra JGM, Ribeiro RLD, Almeida DL, Silva EE \& Urquiaga S Espindola JAA (2007) The use of sunn hemp as green manure intercropped with taro. Horticultura Brasileira, 25:562-566.

Pinto CMF, Vieira RF, Venzon M, Paula Júnior TJ \& Mattos RN (2007) Feijão-vagem (Phaseolus vulgaris L.) In: Paula Júnior TJ \& Venzon M (Eds.). 101 Culturas: Manual de Tecnologias Agrícolas. Belo Horizonte, EPAMIG. p.359-364.

Puiatti M, Greeman S, Katsumoto R \& Favero C (1992) Crescimento e absorção de macronutrientes pelo inhame 'Chinês' e 'Japonês'. Horticultura brasileira, 10:89-92.

Puiatti M, Fávero C, Finger FL \& Gomes JM (2000) Crescimento e produtividade de inhame e de milho doce em cultivo associado. Horticultura Brasileira, 18:24-30.

Puiatti M (2002) Manejo da cultura do taro In: Carmo CAS (Ed.) Inhame e taro: sistemas de produção familiar. Vitória, Incaper. p.203-252.

Ribeiro CA, Guimarães PTG \& Alvares V VH (1999) Recomendações para uso de corretivos e fertilizantes em Minas Gerais: $5^{\text {a }}$ Aproximação. Viçosa, Comissão de Fertilidade do Solo do Estado de Minas Gerais. 359p.

Rubatzky VE \& Yamagushi M (1997) Word vegetables. Principles, production, and nutritive values. $2^{\mathrm{a}}$ ed. New York, Chapman \& Hall. 843p.

SAEG (2007) Sistema para Análises Estatísticas e Genéticas. Versão 9.1. Viçosa, Fundação Arthur Bernardes. CD-ROM.

Salvador DJ, Heredia Zárate NA \& Vieira MC (2003) Produção e renda bruta de cebolinha e de almeirão em cultivo solteiro e consorciado. Acta Scientiarum Agronomy, 26:491-496.

Souza JP, Abboud ACS, Souza CG, Guerra JGM, Espindola JAA \& Ribeiro RLD (2007) Rendimento agronômico de consorcio entre pimentão e feijão vagem arbustivo em sistema orgânico. Seropédica, Embrapa. 4p. (comunicado técnico, 106).

Sullivan P (2001) Intercropping principles and production practices. Disponível em: <www.attra.org/attra-pu/ intercrop.html\#abstratNational>. Acessado em: 14 de junho de 2013.

Vieira C (1998) Cultivos consorciados. In: Vieira C, Paula Júnior TJ \& Borém A (Eds.) Feijão: aspectos gerais e cultura no Estado de Minas Gerais. Viçosa, UFV. p.523-558. 